\title{
Study of Haritreatment on Essential Hypertension
}

\author{
T. IMAI, A. IMAI (Japan)
}

\section{[Preface]}

Mr. Chairman, Ladies and Gentlemen!

The treatment of essential hypertension becomes relatively easy to obtain the blood pressure control owing to a rapid progress of antihypertensive drugs, but these are certain number of patients, who are resistant to these drugs, or cannot be removed their symptoms. We have applied the haritreatment or chiropractic to these patients, alone or in combination with the antihypertensive drugs, and the results are presented here.

\section{[Results]}

At first, I will shortly explain the point of Hari-treatment, which we call Ryodoraku. Ryodoraku has a close resemblance to Meridian which was established in old chinese medicine as the pathway of circulation. In 1957, Dr. Yoshio Nakatani who did electrophysiological study of acupuncture, discovered most of Meridian points of the traditional acupuncture theory corresponded to points which have lower electrical resistance than the normal body surface. Dr Nakatani named these points "Ryodoten" which means hyperelectroconductive points. Further he called the systemic distribution of Ryodoten "Ryodoraku'. He named Lung Meridian as $\mathrm{H}_{1}$ Ryodoraku Meridian, Heart Constrictor Meridian as $\mathrm{H}_{2}$, Spleen Pancreas Meridian, as $\mathrm{F}_{1}$ and so forth.

Slide 1 The Block Diagram of the Equipment using Ryodoraku therapy. The patient holds the grip eleotrode (D) and searching electrode (1) is placed at various points of the body surface in order to find out Ryodoten. A weak direct current of $200 \mu \mathrm{A}$ is delivered to the patient.

Slide 2 This is the Kidney Ryodoraku Meridian, which Dr. Nakatani discovered first.

Slide 3 This is a Kidney Meridian taken from the old chinese book published at 11 th century. It is still used at present time.

Slide 4 There are Excitation Points and Inhibition Points in each Ryodoraku. The slide shows points of excitation and inhibition of Ryodoraku in arms and legs. For example, $\mathrm{H}_{1}$ Ryodoraku in the arm has an excitation point at $\mathrm{H}_{1} 3$ as indicated by circle. Whereas, in $\mathrm{H}_{2}$ Ryodoraku there is an inhibition point at $\mathrm{H}_{2} 3$ as shown by cross. We draw a graph of points of excitation and inhibition in each Ryodoraku from these measurments and this is shown in the next slide.

Slide 5 The slide shows the representative cases of Ryodoraku graph of essential hypertension. In each graph, the top and the bottom lines, indicate, the upper and the lower limit of the normal range, respectively. The points above the mid-line, indicate excitation and those below the mid-line, inhibition. When we give Hari-treatment to these points, the points above or below the mid-eine come closer to this line. We call these treatment as total Ryodoraku adjustment. In chronic diseases, ordinary we do it, and then use local points for various diseases. In acute diseases, we use local points with fewer 
points and stronger stimulation. Chiropractic was done by chiropractor once every week.

Slide 6 The slide shows subjects of our study. There are 348 haritreatment or chiropractic cases of hypertension, who visited to our outpatient clinic last 3 years. We selected 210 cases of Essential Hypertension except heart failure or cerebrovascular diseases, and investigated their symptoms or treatment times. Their ages are ranged from 30-59 years old. If we divided our patients according to the W. H. O.'s classification of minimum B $P$ P (1960), there are 131 cases (62\%) of mild hypertension, 58 cases (27\%) of moderate hypertension, and 21 cases (11\%) of severe hypertension. At last slide, we divided 4 groups and compared the average decrease of $\mathrm{B} \cdot \mathrm{P}$, and improvement of symptoms on 32 cases last year, who belong to W.H.O.'s mild and moderate hypertension.

Slide 7 This slide shows symptoms of cases of essential hypertension on their locations according to chinese medicine. For convenience, if we divide human body into 6 parts and symptoms related to each part are as follows, as you can see part $1+$ part 2 = represented 199 cases $(76 \%)$.

Slide 8 The number of times of haritreatment are $44 \%$ in $1-3$ times, are $32 \%$ in 4-10 times, namely $76 \%$ of cases were treated less than 10 times, it gives great majority of the number of treatment so we have chosen 10 times in 1 Month as 1 treatment period. About 10 times, we get a good control of B P P. 3 times at first week, 2 times in second and third week, then 1 times at every week, and total of 10 times for 1 month were applied.

Slide 9 These representative cases of the haritreatment alone are shown. These 3 cases, which have stiffness of shoulder and sleepless, disappeared after haritreatment; namely 3 times of the treatment improved their symptoms, and decreased their $B \cdot P$, especially minimuna $\mathrm{B} \cdot \mathrm{P}$, but heart rate was unchanged.

Slide 10 These are examples of the long term haritreatment alone these 2 cases, we could control B - P 3 week or half year by haritreatment alone, who could not take drugs because of the side effect. Several years, after stop of the treatment without A drugs, they have good control of B.$P$.

Slide 11 A drug plus chiropractic case. This case, who admitted to the hospital several occasions due to high $\mathrm{B} \cdot \mathrm{P}$, and palpitation, we cannot control her $\mathrm{B} \cdot \mathrm{P}$, by $\mathrm{A}$ drugs. She had also cervical problem, namely dislocation of axis. Her symptoms disappeared after the adjustment of cervical spine, and her blood pressure decreased markedly.

Slide 12 We selected 32 consecutive cases in last year who were treated with same kinds of antihypertensive drugs. Effects of drugs alone, or plus Haritreatmet, or plus chiropractic, or in combination of them are compared. We can see the clear decrease of $\mathrm{B} \cdot \mathrm{P}$, by haritreatment, and improvement of their symptoms.

[summary]

The haritreatment with Ryodoraku method can remove the symptoms related to high B - P, namely vertigo, headache, eyepain, stiffshoulder and it occasionally produce a good control of their B $\cdot \mathrm{P}$. Our result suggest that haritreatment for the treatment of essential hypertension alone, or with the combination of antihypertensive drugs, is a usefull method. Thank you for your attention.

(This was presented in 17 th international interval congress at Kyoto Japan.) 


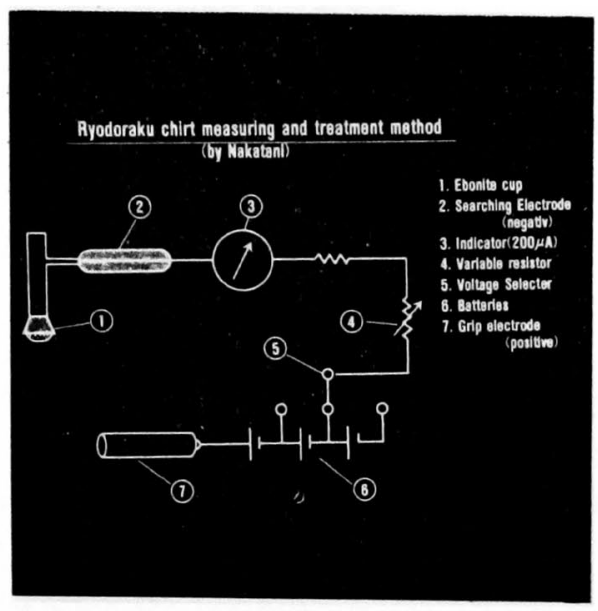

Slide (1)

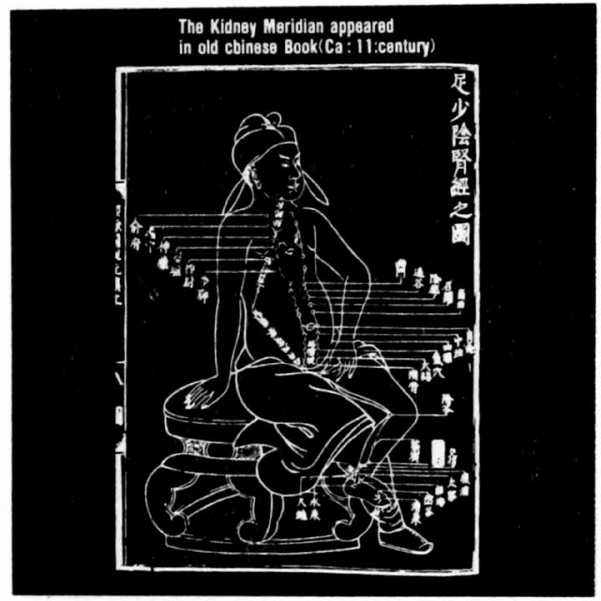

Slide (3)

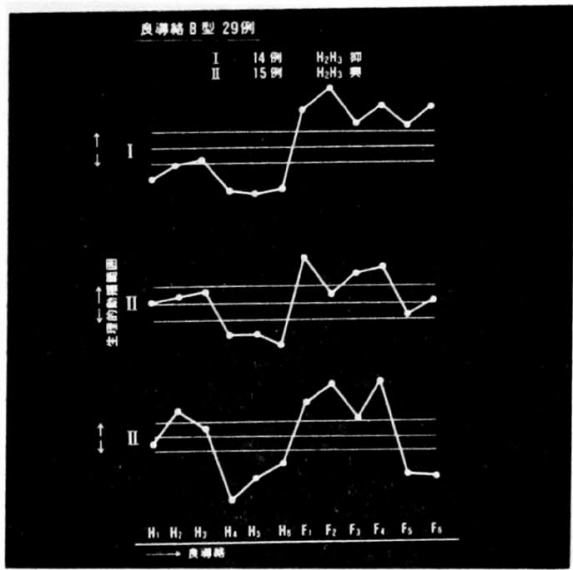

Slide (5)
The Kidney Meridian(by RYODORAKU)

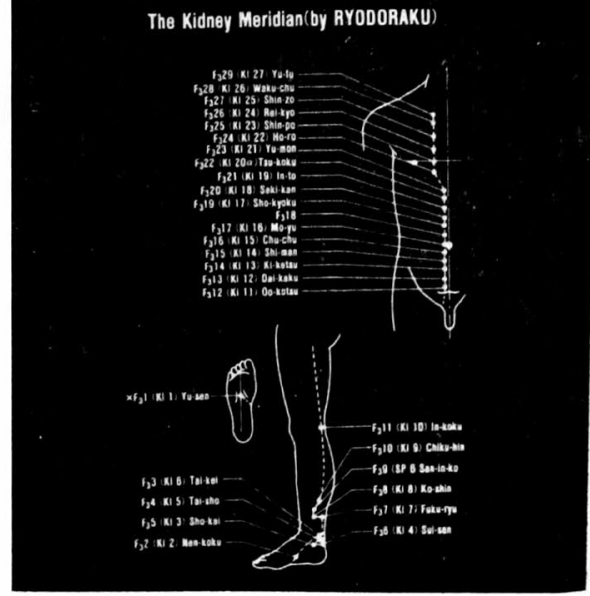

Slide (2)

Excitation and Inhibition points

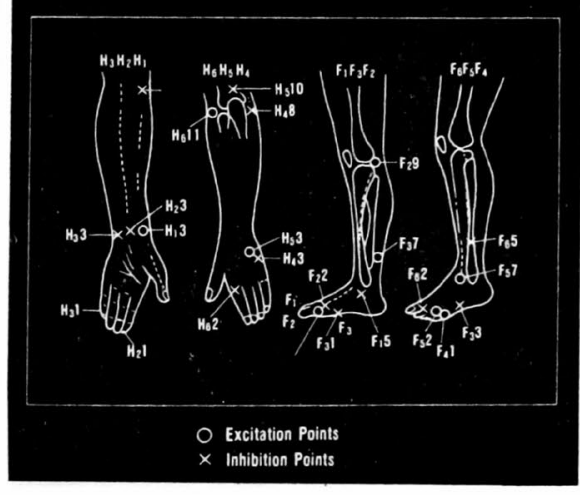

Slide (4)

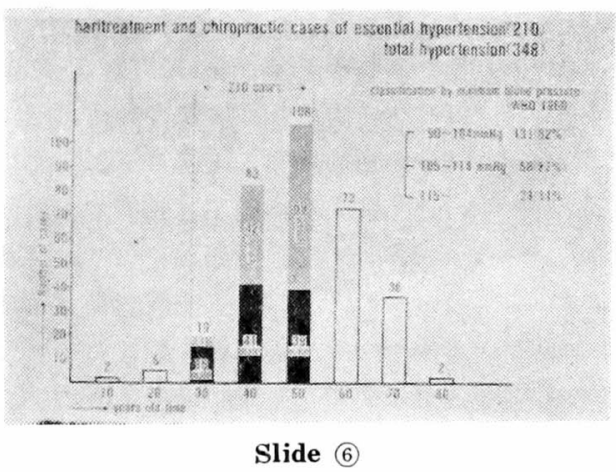




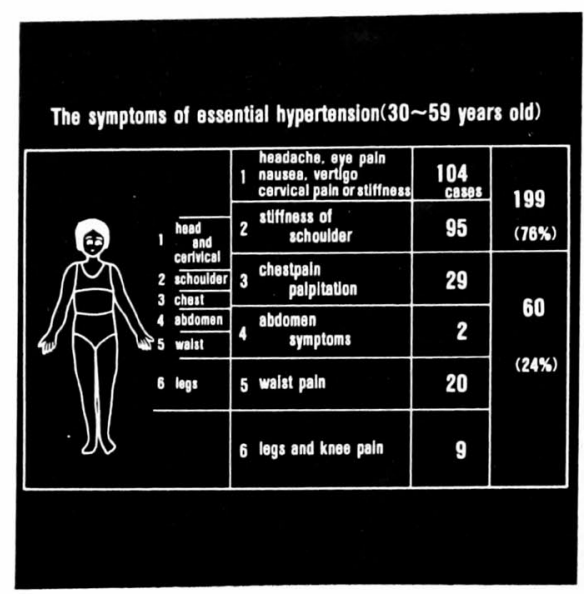

Slide (7)

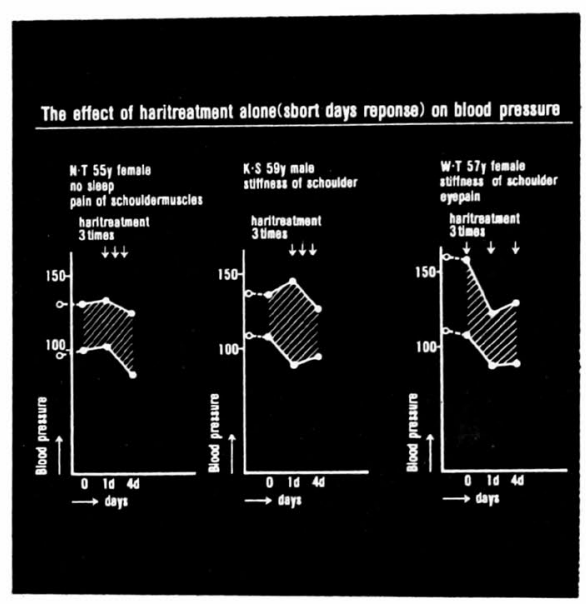

Slide (9)

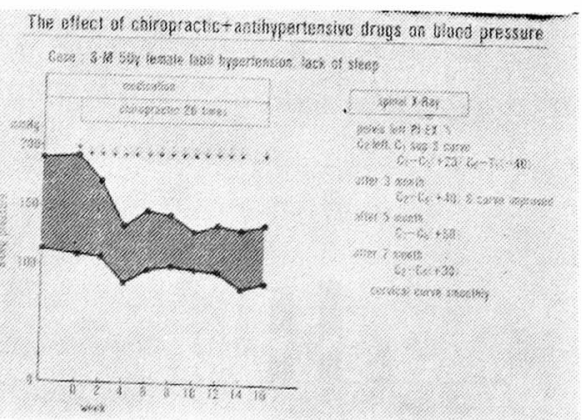

Slide (11)

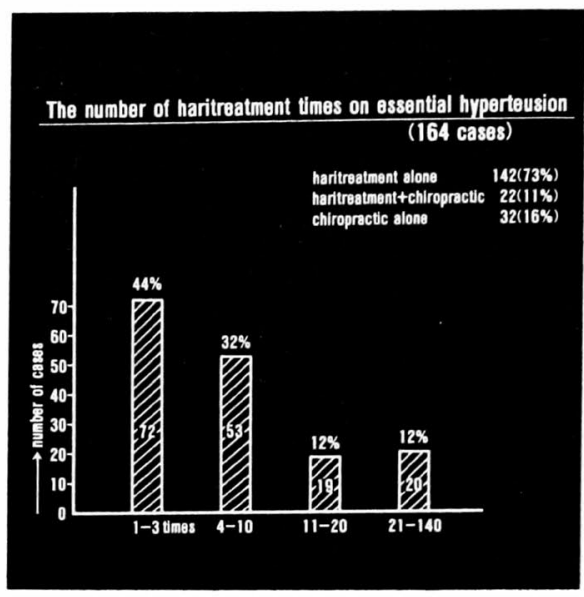

Slide (8)

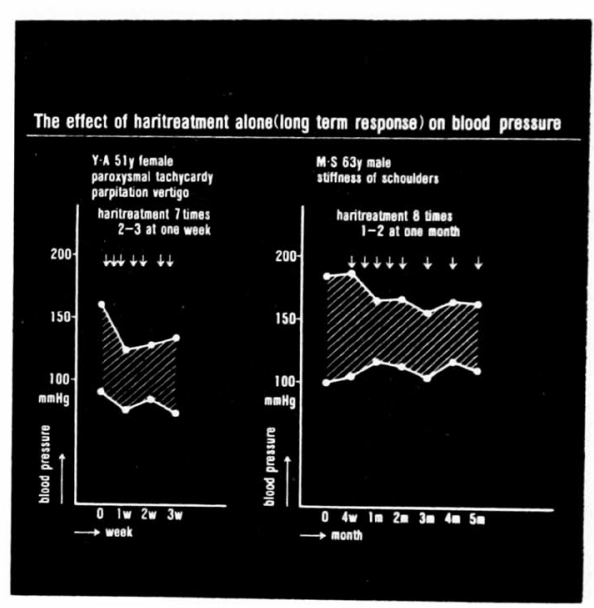

Slide (10)

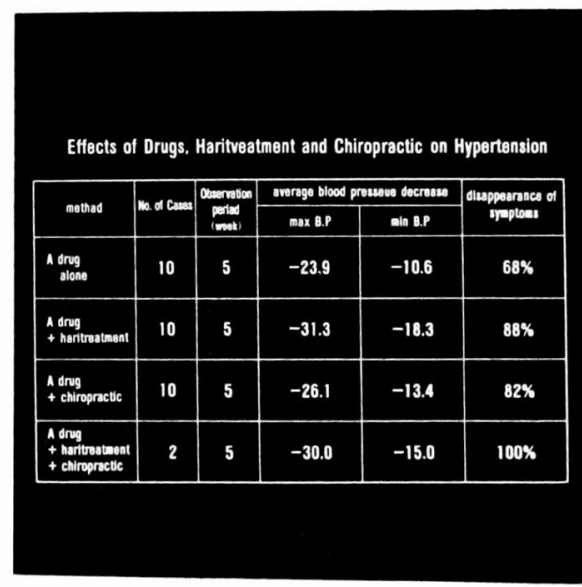

Slide (12) 